\title{
Incipient Motion of Gravel Bedload Considering the Secondary Flow in Bend
}

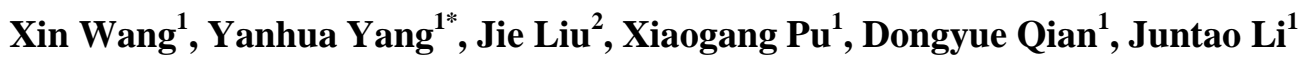 \\ ${ }^{I}$ Tianjin Research Institute of Water Transport Engineering, Key Laboratory of Engineering Sediment of \\ Ministry of Communications, Tianjin, China \\ ${ }^{2}$ National Inland Waterway Regulation Engineering Research Center, Chongqing Jiaotong University, \\ Chongqing, China \\ *Corresponding Author.
}

\begin{abstract}
The transport of gravel bedload in river bend is one of the basic problems of river dynamics. However, both the complicated bend flow structure and the stochastic bedload transport make explaining the problem theoretically difficult. Flow is the power of the bedload transport, so obtaining the precise theoretical flow structure is fundamental. Through considering the velocity-dip phenomenon and giving the matched boundary conditions, we have obtained the completed three-dimensional bend flow structure in the previous study. Combining the flow structure and the influences of the two-way exposure, we did further research on the incipient motion of the gravel bedload in bend in this paper. It turns out that, because of the existence of the secondary flow, the particle in bend forced by both the longitude and the transverse velocities in the plane. The two-way velocities form an intersection angle which influences the incipient velocity and direction of the particle movement. Moreover, the non-uniform distribution of the bend flow structure along the cross-section decides the differences of the intersection angle, incipient velocity, transport speed of the bedload in the bed surface. Then, the above differences result in the change of the sediment gradation and partition behaviour of the bedload transport.
\end{abstract}

Keywords: Bend flow, three-dimensional structure, gravel bedload, two-way exposure, incipient velocity, direction of transport

\section{Introduction}

It is very effective and necessary to carry out artificial channelization projects in some key river sections, so as to make full use of the natural conditions of water conservancy and improve the navigation conditions of the waterway. However, for the river dynamic system, changes in boundary conditions (such as water level, flow, and incoming sediment replenishment after the completion and operation of the channelization project) will directly affect the hydrodynamic flow field of the corresponding river section, and then affect the shape of the river bed. Conversely, the change of the river bed shape will directly affect the practicability and safety of the corresponding channelization project. Therefore, it becomes very necessary to carry out the prediction and calculation of the evolution law of the riverbed. As the curved river section is the most basic unit that constitutes a natural river, the erosion and siltation of the riverbed in the bend is the most common. The evolution of the riverbed starts when the sediment moves due to the corresponding water flow action and is transported along the corresponding water flow direction. The water flow in a bend has a special three-dimensional flow structure which is different from that of a straight river. As a dynamic field driving the movement of sediment, it directly affects the moving conditions of the sediment in the bend and the subsequent transport movement. The water flow in a bend has a special threedimensional flow structure which is different from that of a straight river. As a dynamic field driving the movement of sediment, it directly affects the incipient motion conditions of the sediment in the bend and the subsequent transport movement. At the same time, the three main navigable river basins in China are the Songhua River, the Yangtze River and the Pearl River basins. Among them, the Songhua River Dadingzishan Hub

ISSN: 0010-8189

(C) CONVERTER 2020

www.converter-magazine.info 
Channel ${ }^{[1]}$, the Yangtze River above Yichang Channel $^{[2]}$, and the Beijiang River Upper Channel ${ }^{[3]}$ are typical sandy gravel riverbeds. Therefore, the accurate calculation of the gravel movement law under the action of bend flow has strong practical engineering value.

Gravels move on the bed surface, mainly with bedload movement. As one of the basic problems of river dynamics, bedload movement has always attracted the attention of a large number of scholars. The bed surface of natural rivers is mostly composed of non-uniform sediment. The mutual positional relationship of non-uniform sediment on the bed surface is the basis for in-depth study of the characteristics of non-uniform bedload movement. Einstein $^{[4]}$, Misri et al. ${ }^{[5]}$, Samaga ${ }^{[6]}$, Mittal ${ }^{[7]}$ and Patel and Ranga ${ }^{[8]}$ introduced different forms of "concealment coefficient" to consider the phenomenon of mutual concealment when non-uniform sediment starts to move. Han Qiwei ${ }^{[9-11]}$ systematically proposed the concept of relative exposure of sediment particles to reflect the randomness of the position of sediment particles on the bed surface, and also introduced it into the study of non-uniform sediment movement. Liu Xingnian et al. ${ }^{[12]}$ combined the exposure height with the average height of the bed surface, and used the positive or negative of the exposure height to reflect the position of the sediment particles relative to the average bed surface, and also pointed out the direct effect of the position of the bed surface on the flow force suffered by the particles. Bai Yuchuan et al. introduced relative exposure to the process of starting and movement of non-uniform sediment on different bed surfaces and in different states ${ }^{[13-16]}$, proposed the concept of two-way exposure ${ }^{[17]}$ for the first time, fully considered the random positional relationship between the sediment particles, and analyzed the influence of the positional relationship on the starting conditions of the sediment.

The upstream incoming flow is the source power of the sediment movement, and the dynamic field determines whether the bedload has incipient motion or transport and the direction of the transport, as well as the location of silt and the final bed structure. Lu Yongjun and Zhang Huaqing ${ }^{[18]}$ pointed out that the bedload transport is affected by water flow, and the non-uniform distribution of the water flow conditions determines the non-uniformity of sediment transport volume and gradation of the bedload. Moreover, Teraguchi et al. ${ }^{[19]}$, Lu et al. ${ }^{[20]}$, and Liu et al. ${ }^{[21]}$ all explained the influence of water flow structure on sediment movement from different perspectives. Due to its special bank boundary conditions, curved rivers have a special three-dimensional flow structure that is different from straight rivers. That is, there is a secondary circulation structure in the section outside the main flow along the flow direction. And such circulation structure directly affects the movement of sediment on the curved river bed. Furthermore, based on the observations of the circulation structure of the Colorado River and other rivers, Leopold pointed out that the bedload movement is affected by the secondary circulation of the bend, and the main area is on the side of the convex beach ${ }^{[22]}$. Li Zhiwei and Fang Chunmin ${ }^{[23]}$ found from their research that the sediment movement on the curved bed surface is affected by the lateral circulation, and the bedload is closely related to the vertical and horizontal near-bottom velocities and the lateral bottom slope. Parker et al. ${ }^{[2]}$ considered that there are two-way sediment transport in the bend, i.e. the longitudinal transport and the lateral transport corresponding to the main flow and the lateral flow velocity of the section respectively, and put forward the general formula for the lateral sediment transport intensity of the bedload in the bend and the mathematical model for calculating the sediment separation of the bed in the bend. It is found from the study that the three-dimensional flow velocity in the curved section all presents a non-uniform distribution law along the width of the section, so the incipient motion and transportation of bedload is also non-uniform along the width of the section. Clayton et al. ${ }^{[25]}$ observed the variability of bedload transport in a $180^{\circ}$ bend of the Colorado River in the field, indicating that the coarse and fine bedload particles in the bend move in different directions, and the coarse particles will move from the concave bank to the center of the channel, resulting in horizontal separation of particles. Besides, Jia Dongdong et al. ${ }^{[26]}$ also pointed out that when calculating the bedload scouring deformation of a bend, the choice of the direction of the bedload transfer has a significant impact on the erosion result, and it cannot be simply assumed to be consistent with the average flow velocity along the vertical. Instead, full consideration should be given to the impact of the near-bottom water flow on the load transport.

It is found from the statistics of existing research results that the theoretical research on the influence of the non-

ISSN: 0010-8189

(C) CONVERTER 2020

www.converter-magazine.info 
uniform three-dimensional flow structure of the bend flow on the bed surface movement of the gravel is still insufficient due to the complicated bend flow structure and the stochastic gravel incipient motion. Based on this background, this paper, on the basis of the relatively complete three-dimensional flow structure of the open channel in the bend ${ }^{[27]}$, further analyzed the start law of the non-uniform gravel in the bend considering the effect of two-way exposure, obtained the theoretical solution of the incipient motion flow velocity of the gravel in the bend, and also analyzed the influence of the circulation in the bend on the incipient motion and transport of sediment.

\section{Theoretical Model of Sediment Incipient Motion Under the Influence of Secondary Flow in Bend}

\subsection{Bend flow structure considering velocity-dip phenomenon}

The upstream incoming flow condition is the dynamic field of sediment movement, and the accurate calculation of the three-dimensional flow structure of the bend is the prerequisite for calculating the law of sediment movement under the influence of the secondary flow of the bend.

Bai Yuchuan and Wang Xin used orthogonal curvilinear coordinate system to generalize the natural bend flow movement ${ }^{[27]}$, as shown in Fig. 1, and split the three-dimensional flow velocity into the main flow control part and the secondary flow control part for solution ${ }^{[27-29]}$, as shown in Formula (1). In the process of solving, it is found that the three-dimensional flow velocity of the open channel flow in the bend has velocity-dip (the position of the maximum flow velocity of the main flow is below the free water surface ${ }^{[30-32]}$, and the position of the secondary circulation vortex core is below the half-water depth of the section ${ }^{[27]}$ ), as shown in Fig. 2. By introducing a modified logarithmic wake flow rate, as shown in Formula (2), the velocity sinking phenomenon is fully considered, and a complete dimensionless bend open channel three-dimensional flow structure is obtained, as shown in Formulas (3)-(5).

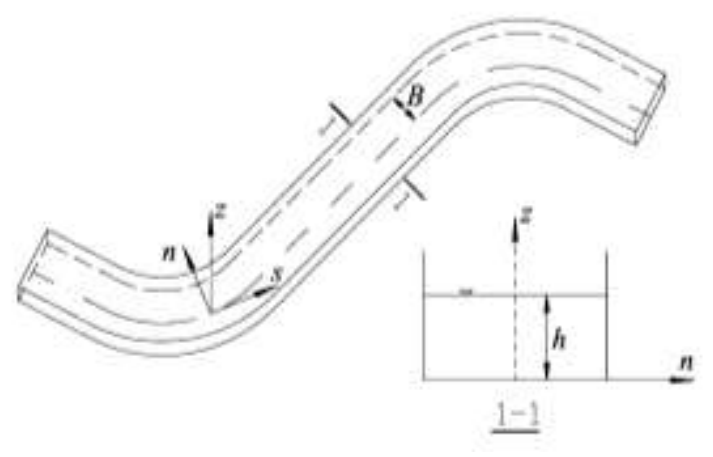

Fig 1: Orthogonal curvilinear coordinate system

Fig. 1 shows a bend river channel generalized by orthogonal curvilinear coordinate system $(s, n, z), s$ : along the flow direction (longitudinal); $n$ : along the transverse direction of the section; $z$ : along the vertical direction of the section, with upward perpendicular to the river bed as the positive direction; $h$ is the water depth value; $B$ is the half river width value.

ISSN: 0010-8189 


$$
\begin{gathered}
u_{s}=\overline{u_{s}}(s, n) T(\zeta) \\
u_{n}=\overline{u_{n}}(s, n) T(\zeta)+v \\
u_{z}=\overline{u_{z}}(s, n) T(\zeta)+w
\end{gathered}
$$

Where $u_{i}(i=s, n, z)$ is the velocity component in the $i$ direction in the bend; $\bar{u}_{i}$ is the vertical average value of $u_{i}$, which can be regarded as the main flow control velocity component; $v$ is the transverse velocity component of the secondary circulation; $w$ is the vertical velocity component of the secondary circulation. Under the premise of velocity splitting, $\overline{u_{\imath}} T$ in formula (1a-1c) represents the velocity component caused by the elementary flow, and $v(w)$ represents the velocity component caused by the secondary flow. Therefore, on the basis of velocity splitting, a coupling model formed by the depth formula and the three-dimensional governing formula can be used to effectively solve the bend flow field.
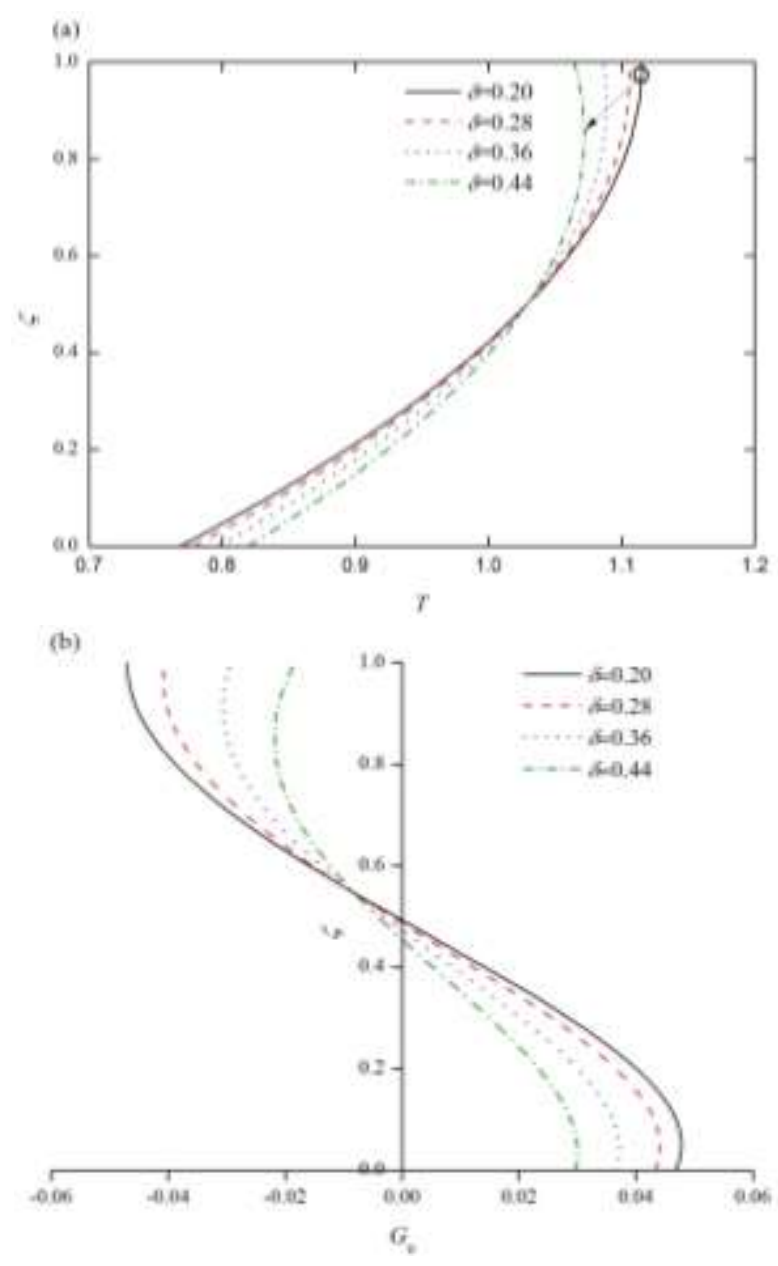

ISSN: 0010-8189 


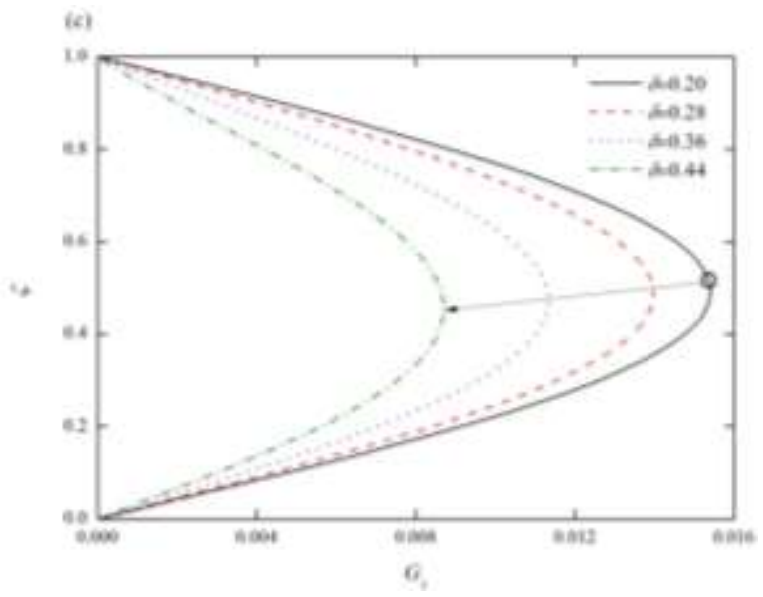

Fig 2: Three-dimensional velocity-dip phenomenon: (a) Longitudinal velocity; (b) Transverse velocity; (c) Vertical velocity

Fig. 2 shows the three-dimensional velocity-dip phenomenon in the bend open channel flow calculated by Yuchuan Bai and Xin Wang through the coupling model, where 2(a) is the distribution of the dimensionless vertical distribution function $T(\zeta)$ of the longitudinal velocity along the relative water depth $\zeta, 2(\mathrm{~b})$ is the distribution of the dimensionless vertical distribution function $G_{0}(\zeta)$ of the transverse velocity along the relative water depth, 2(c) is the distribution of the dimensionless vertical distribution function $G_{1}(\zeta)$ of the vertical velocity along the relative water depth. It can be seen intuitively from the figure that as the section becomes narrower and deeper (the width-to-depth ratio $\delta$ becomes larger), the three-dimensional flow velocity dips respectively. Specifically, the position of the maximum velocity of the vertical main flow velocity gradually dips from the free water surface, and the position of the secondary circulation vortex core (which can be represented by the position of the horizontal velocity zero and the position of the maximum vertical velocity) gradually dips from the halfwater depth of the section.

$$
\frac{u_{s 0}^{*}(0, \zeta)}{u_{* b}^{*}}=\frac{1}{\kappa}\left[\ln \frac{\zeta}{\zeta_{0}}-\frac{1}{3}\left(\frac{\zeta}{\beta}\right)^{3}\right]+(1+\sqrt{\alpha}) \sin ^{2} \frac{\pi \zeta}{2 \beta}
$$

Where $u_{s 0}^{*}$ is the dimensionless flow velocity in the $s$ direction that is not affected by the bend; $u_{* b}^{*}$ is the dimensionless bed shear flow velocity; $\kappa$ is the Karman constant; $\zeta_{0}$ is the relative position where the velocity is zero determined by the logarithm law; $\beta$ is the relative position of the velocity dip, $\beta=\left\{1+\exp -[2 /(\pi \delta)]^{3 / 2}\right\}^{-1} ; \alpha$ is the ratio of the water surface to the bed surface shear stress, $\alpha=(1-\beta) / \beta$.

$$
\begin{aligned}
& u_{s}^{*}={\overline{u_{s}}}^{*} T(\zeta)
\end{aligned}
$$

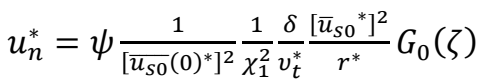

$$
\begin{aligned}
& u_{z}^{*}=-\psi \frac{1}{\left[\bar{u}_{s 0}(0)^{*}\right]^{2}} \frac{1}{\chi_{1}^{2}} \frac{\delta}{v_{t}^{*}} \frac{2 \bar{u}_{s 0^{*}}}{r^{*}} \frac{\partial \bar{u}_{s 0^{*}}}{\partial n^{*}} G_{1}(\zeta)
\end{aligned}
$$

Where $u_{i}^{*}(i=s, n, z)$ is the dimensionless three-dimensional flow field in the bend; $r^{*}$ is the dimensionless radius of curvature of the bend; $v_{t}^{*}$ is the dimensionless viscosity coefficient; $\psi$ is the bending coefficient, which is the ratio of the half-river width to the minimum radius of curvature; $\chi_{1}$ is the calculation coefficient, $\chi_{1}=\alpha_{2} / \sqrt{C_{f}}$, $\alpha_{2}=0.077^{[33]}, C_{f}$ is the dimensionless Chezy coefficient, $C_{f}=g H S_{0} / U^{2}, H$ is the average water depth of the section, $S_{0}$ is the average slope of the bend, and $U$ is the average velocity of the section.

ISSN: 0010-8189 
The relevant parameters in the above formula are calculated as follows:

$$
\begin{gathered}
\bar{u}_{s}^{*}=\bar{u}_{s 0}{ }^{*}+\psi \bar{u}_{s 1}{ }^{*} \\
T=\frac{1}{\bar{u}_{s 0}(0)^{*}} \frac{1}{\chi_{1}}\left(\beta \zeta-\frac{1}{2} \zeta^{2}+\chi\right) \\
G_{0}(\zeta)=\frac{1}{120} \zeta^{6}-\frac{1}{20} \zeta^{5}+\frac{1}{12}\left(\beta^{2}-\chi\right) \zeta^{4}+\frac{1}{3} \beta \chi \zeta^{3}+\frac{1}{2} \chi^{2} \zeta^{2}-\left(\zeta+\frac{\chi}{\beta}\right)\left(\frac{2}{15} \beta^{5}+\frac{2}{3} \chi \beta^{3}+\chi^{2} \beta\right) \\
+\frac{1}{2}\left[\bar{u}_{s 0}(0)^{*}\right]^{2} \chi_{1}^{2} \chi_{20} \zeta^{2}-\left[\bar{u}_{s 0}(0)^{*}\right]^{2} \chi_{1}^{2} \chi_{20} \beta\left(\zeta+\frac{\chi}{\beta}\right) \\
G_{1}(\zeta)=\frac{1}{840} \zeta^{7}-\frac{1}{120} \beta \zeta^{6}+\frac{1}{60}\left(\beta^{2}-\chi\right) \zeta^{5}+\frac{1}{12} \beta \chi \zeta^{4}+\left[\frac{1}{6} \chi^{2}+\frac{1}{6} \bar{u}_{s 0}(0)^{* 2} \chi_{1}^{2} \chi_{20}\right] \zeta^{3} \\
-\left(\frac{1}{2} \zeta^{2}+\frac{\chi}{\beta} \zeta\right)\left[\frac{2}{15} \beta^{5}+\frac{2}{3} \chi \beta^{3}+\chi^{2} \beta+\bar{u}_{s 0}(0)^{* 2} \beta \chi_{1}^{2} \chi_{20}\right]
\end{gathered}
$$

Where $\bar{u}_{s 1}{ }^{*}$ is the dimensionless $s$-direction velocity component affected by the first order of bending; $\chi$ and $\chi_{20}$ are calculation coefficients. The specific calculation methods of the above correlation coefficients and parameters can be found in published literature ${ }^{[27]}$.

\subsection{Bend flow structure considering velocity-dip phenomenon}

\subsubsection{Force analysis}

Different from straight rivers, in addition to the longitudinal main flow $u_{s}$, there are horizontal flow velocity $u_{n}$ and 0vertical flow velocity $u_{z}$ in the section of the bend flow. The three-dimensional flow velocity superimposes to form a typical spiral flow structure, as shown in Fig. 3.

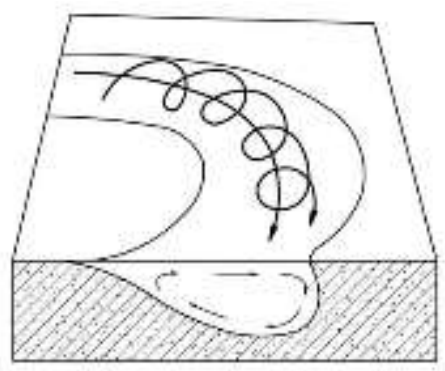

Fig 3: Spiral flow

The transport characteristics of bottom load in bends are mainly related to the vertical and horizontal near-bottom velocity ${ }^{[34-36]}$. Therefore, the gravel particles on the bend bed are simultaneously subjected to the combined action of the longitudinal instantaneous bottom velocity $u_{s b}$ and the transverse instantaneous bottom velocity $u_{n b}$. The twoway flow velocity acts on the sediment particles on the bed surface to form an included velocity angle, as shown in Formula (10).

$$
\tan \theta=u_{n b} / u_{s b}
$$

The included angle can be defined as the curl value of the secondary circulation, reflecting the strength of the

ISSN: 0010-8189

(C) CONVERTER 2020 
secondary circulation at that location. At the same time, for a natural bend river that forms a curvilinear orthogonal, the degree of curvature of the bend affects the included angle of the flow velocity.

The gravel particles are randomly arranged on the bed surface, and the longitudinal and vertical two-way exposures are selected to reflect their random positions ${ }^{[17]}$, and the No. 4 particle is the object of force analysis, as shown in Fig. 4(a), where $\Delta_{z}$ is the vertical exposure and $\Delta_{x}$ is the vertical exposure. The exposure degree is nondimensionalized with 2 times sediment particle size, and the two-way relative exposure degree is obtained. The two-way exposure degree is randomly distributed and has a probability distribution function like Formulas (11)(14). No. 4 particle is in a critical incipient motion state in a bend with a rectangular cross-section, and is subjected to the combined action of the force of the water current and its own underwater gravity, as shown in Fig. 4(b). Under the action of the bend flow, the sediment particles are subjected to the drag force $F_{D S}$ caused by the longitudinal velocity, the drag force $F_{D n}$ caused by the lateral velocity, the uplift force $F_{L s}$ caused by the longitudinal velocity, the uplift force $F_{L n}$ caused by the lateral velocity, and the underwater gravity $W$. Considering the regular shape (spherical) of the gravel here, the distances from the point of action of $F_{D s}, F_{D n}, F_{L s}$, and $F_{L n}$ to the center of the circle are all taken as $D / 6^{[17]}$, and the expressions of the above-mentioned forces are shown in Formulas (15) (19) .

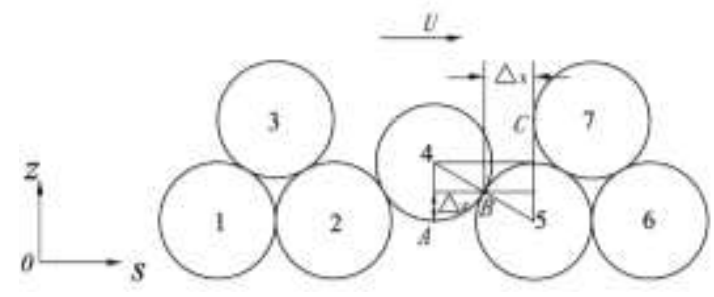

(a) Schematic diagram of two-way exposure

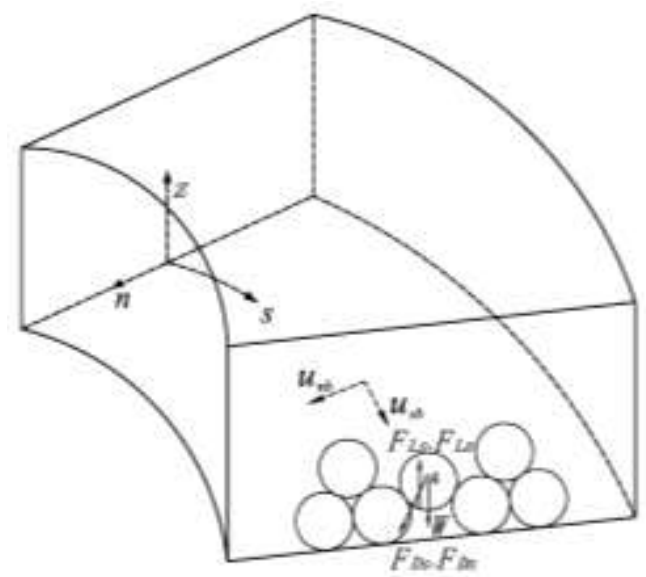

(b) Force analysis of gravel under the action of bend flow

ISSN: 0010-8189 
Fig 4: Random distribution and force diagram of gravel particles on bend bed

Vertical relative exposure:

Uniform sediment

$$
\mathrm{F}\left(\Delta_{z}^{\prime}\right)=\left\{\begin{array}{lr}
1 & \left(\Delta_{z}^{\prime}>1\right) \\
\frac{\Delta_{z}^{\prime}-0.134}{0.866} & \left(\Delta_{z m}^{\prime} \leq \Delta_{z}^{\prime} \leq 1\right) \\
0 & \left(\Delta_{z}^{\prime}<\Delta_{z m}^{\prime}\right)
\end{array}\right.
$$

Non-uniform sediment

$$
\mathrm{F}\left(\Delta_{l z}^{\prime}\right)=\left\{\begin{array}{cc}
1 & \left(2^{\text {nd level: }} \Delta_{l z}^{\prime}>\frac{\bar{D}}{D_{l}} ; 3^{\text {rd level: } \left.\Delta_{l z}^{\prime} \geq 1\right)}\right. \\
\frac{\Delta_{l z}^{\prime}-\Delta_{z m}^{\prime}}{\frac{D}{D_{l}}-\Delta_{z m}^{\prime}} & \left(2^{\text {nd }} \text { level: } \Delta_{z m}^{\prime} \leq \Delta_{l z}^{\prime} \leq \frac{\bar{D}}{D_{l}} ; 3^{\text {rd }} \text { level: } \Delta_{z m}^{\prime} \leq \Delta_{l z}^{\prime} \leq 1\right) \\
0 & \text { (other cases) }
\end{array}\right.
$$

Longitudinal relative exposure:

Uniform sediment

$$
\mathrm{F}\left(\Delta_{x}^{\prime}\right)=\left\{\begin{array}{cc}
1 & \left(\Delta_{x}^{\prime}>1\right) \\
\frac{0.866-\sqrt{1-\left(\Delta_{x}^{\prime}\right)^{2}}}{0.866} & \left(0.5 \leq \Delta_{x}^{\prime} \leq 1\right) \\
0 & \left(\Delta_{x}^{\prime}<0.5\right)
\end{array}\right.
$$

Non-uniform sediment

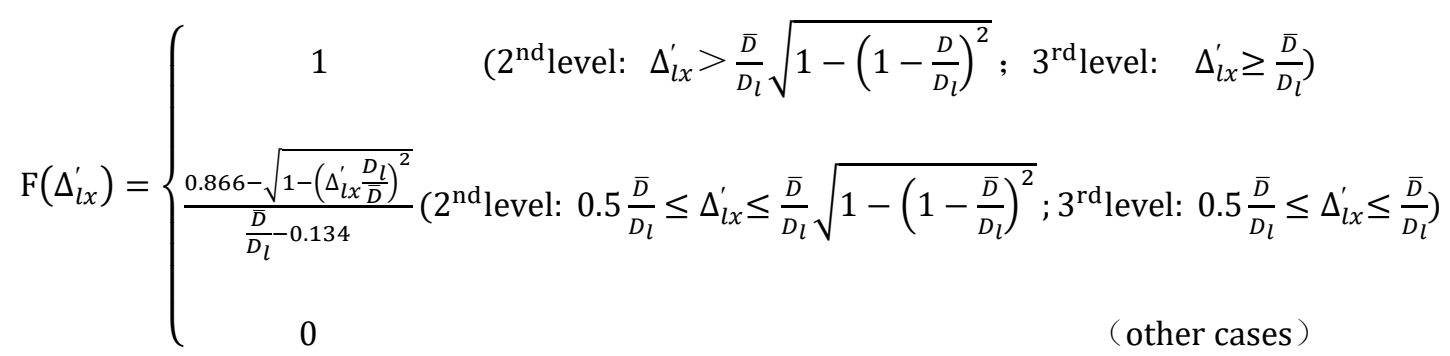

Where $\Delta_{Z}^{\prime}$ is the relative vertical exposure, $\Delta_{z}^{\prime}=\Delta_{\mathrm{z}} / 2 D ; \Delta_{l z}^{\prime}$ is the vertical relative exposure of the non-uniform sediment grouping, $\Delta_{l z}^{\prime}=\Delta_{\mathrm{lz}} / 2 D_{l} ; \Delta_{x}^{\prime}$ is the longitudinal relative exposure, $\Delta_{x}^{\prime}=\Delta_{\mathrm{x}} / 2 D ; \Delta_{l x}^{\prime}$ is the vertical longitudinal relative exposure of the non-uniform sediment grouping, $\Delta_{l x}^{\prime}=\Delta_{l x} / 2 D_{l} ; D$ is the sediment particle size; $D_{l}$ is the non-uniform sediment grouping particle size. For ease of expression, the symbol of the non-uniform

ISSN: 0010-8189 
sediment particle size group $l$ is omitted in the following derivation process.

$$
\begin{aligned}
& F_{D s}=\frac{C_{D} \rho}{2} \frac{\pi}{4} D^{2} u_{s c b}{ }^{2} \\
& F_{D n}=\frac{C_{D} \rho}{2} \frac{\pi}{4} D^{2} u_{n c b}{ }^{2} \\
& F_{L s}=\frac{C_{L} \rho}{2} \frac{\pi}{4} D^{2} u_{s c b}^{2} \\
& F_{L n}=\frac{C_{L} \rho}{2} \frac{\pi}{4} D^{2} u_{n c b}{ }^{2} \\
& W=\left(\rho_{s}-\rho\right) g \frac{\pi}{6} D^{3}
\end{aligned}
$$

Where $u_{s c b}$ is the critical instantaneous bottom velocity of the sediment particles in the $s$ direction; $u_{n c b}$ is the critical instantaneous bottom velocity of the sediment particles in the $n$ direction; $C_{D}$ is the current drag coefficient; $C_{L}$ is the current uplift force coefficient; $\rho$ is the water density; $\rho_{s}$ is the density of sediment.

Bai Yuchuan and Wang Xin et al. based on the fine simulation of the water flow structure between large particle size gravels $(D=20-200 \mathrm{~mm})$, found that the random arrangement of gravels resulted in bidirectional exposure and formed corresponding vortex areas, making the sediment particles superimposed locally and affected by vortex, and the change of local flow structure directly affects the flow force of sediment, which is manifested in the change of the corresponding force coefficient. Based on numerical analysis, the uplift force coefficient $C_{L}$ and drag force coefficient $C_{D}$ are functions of longitudinal exposure and particle Reynolds number, as shown in Formulas (20)(21).

$$
\begin{gathered}
\mathrm{C}_{\mathrm{D}}=-1.306+11.617 \overline{\Delta_{l x}^{\prime}}-17.511{\overline{\Delta_{l x}^{\prime}}}^{2}+8.417{\overline{\Delta_{l x}^{\prime}}}^{3} \\
\mathrm{C}_{\mathrm{D}}=-2.378+14.994 \overline{\Delta_{l x}^{\prime}}-21.616{\overline{\Delta_{l x}^{\prime}}}^{2}+9.950{\overline{\Delta_{l x}^{\prime}}}^{3}+26.924 \exp \left(-3.534 \times 10^{-4} \mathrm{Re}_{*}\right)
\end{gathered}
$$

Where $\overline{\Delta_{l x}^{\prime}}$ is the expected value of longitudinal relative exposure, as calculated by Formulas (13) and (14).

2.2.2 Rolling incipient motion model

Taking the rolling of No. 4 particle as the critical condition, the contact point of the No. 4 particle and its downstream is used as the rolling fulcrum to establish a torque balance formula as Formula (22).

$$
\left(F_{D s}+F_{D n}\right)\left(\frac{2}{3} D-\overline{\Delta_{l z}}\right)+\left(F_{L s}+F_{L n}\right)\left[\frac{1}{6} D+\sqrt{\overline{\Delta_{l z}}\left(D-\overline{\Delta_{l z}}\right)}\right]=W \sqrt{\overline{\Delta_{l z}}\left(D-\overline{\Delta_{l z}}\right)}
$$

Where $\bar{\Delta}_{l z}$ is the expected value of the vertical exposure.

Entering the relevant variable expression into Formula (22), the vertical critical incipient motion bottom velocity can be obtained as:

$$
u_{s c b}=\varphi\left(\overline{\Delta_{x}^{\prime}}, \overline{\Delta_{z}^{\prime}}\right) \frac{1}{\sqrt{1+\tan ^{2}(\theta)}} \sqrt{\frac{4}{3} \frac{\rho_{s}-\rho}{\rho} g D}
$$

ISSN: 0010-8189 
Where $\varphi\left(\overline{\Delta_{x}^{\prime}}, \overline{\Delta_{z}^{\prime}}\right)$ is the incipient motion velocity influence function under the influence of the two-way relative exposure, calculated as Formula (24); $\tan \theta$ is the included angle of the velocity of the bend flow, calculated as Formula (10).

$$
\varphi\left(\overline{\Delta_{x}^{\prime}}, \overline{\Delta_{Z}^{\prime}}\right)=\left\{\frac{\sqrt{\frac{1}{2} \overline{\Delta_{Z}^{\prime}}\left(1-\frac{1}{2} \overline{\Delta_{z}^{\prime}}\right)}}{\mathrm{C}_{\mathrm{D}}\left(\frac{2}{3}-\frac{1}{2} \overline{\Delta_{Z}^{\prime}}\right)+\mathrm{C}_{\mathrm{L}}\left[\frac{1}{6}+\sqrt{\frac{1}{2} \overline{\Delta_{Z}^{\prime}}\left(1-\frac{1}{2} \overline{\Delta_{Z}^{\prime}}\right)}\right]}\right\}^{1 / 2}
$$

The instantaneous bottom velocity is a random variable. According to the results of Mr. Dou Guoren's research, under the middle movement standard, the instantaneous bottom velocity has the following relationship with its time average ${ }^{[17]}$ :

$$
\hat{u}_{s c b}=\frac{1}{1+0.37 \times 2} u_{s c b}=0.575 u_{s c b}
$$

Where $\hat{u}_{s c b}$ is the longitudinal time average bottom velocity of water flow acting on sediment particles.

Therefore, the expression of the incipient motion time average bottom velocity of the sediment particles in the longitudinal direction is:

$$
\hat{u}_{s c b}=0.575 \varphi \frac{1}{\sqrt{1+\tan ^{2} \theta}} \sqrt{\frac{4}{3} \frac{\rho_{s}-\rho}{\rho} g D}
$$

\subsubsection{Model validation}

In this paper, the actual measurement data of Clayton and Pitlick ${ }^{[25]}$ and the incipient motion data of the sediment on the slope of the concave bank of the river bend under the middle motion standard from the test by Zhang Qizhe $^{[37]}$ are selected to verify the gravel incipient motion formula under the action of the bend flow. The

\begin{tabular}{|c|c|c|c|c|c|c|c|c|c|c|}
\hline $\begin{array}{c}\text { Data } \\
\text { sources }\end{array}$ & $\begin{array}{c}\text { Quantit } \\
\mathrm{y} \\
\left(\mathrm{L} \cdot \mathrm{S}^{-1}\right)\end{array}$ & $\begin{array}{c}\text { Slope } \\
\text { coefficient } \\
\text { M }\end{array}$ & $\begin{array}{c}\text { Diamet } \\
\text { er } \\
(\mathrm{mm})\end{array}$ & $\begin{array}{c}\text { Dept } \\
\text { h } \\
(\mathrm{m})\end{array}$ & $\begin{array}{c}\text { Chezy } \\
\text { coefficie } \\
\text { nt } \\
\text { C }\end{array}$ & $\begin{array}{l}\text { Radiu } \\
\text { S } \\
(\mathrm{m})\end{array}$ & $\begin{array}{c}\text { Calculat } \\
\text { ed value } \\
(\mathrm{m} / \mathrm{s})\end{array}$ & $\begin{array}{c}\text { Measure } \\
\text { d value } \\
(\mathrm{m} / \mathrm{s})\end{array}$ & $\begin{array}{l}\text { Error } \\
(\mathrm{m} / \mathrm{s})\end{array}$ & $\begin{array}{l}\text { Relativ } \\
\text { e error }\end{array}$ \\
\hline \multirow{3}{*}{$\begin{array}{c}\text { Clayton } \\
\text { and } \\
\text { Pitlick }_{5]}^{[2}\end{array}$} & 10500 & - & 1 & 0.61 & 29.02 & 36.1 & 0.9819 & 0.4096 & $\begin{array}{c}0.572 \\
3 \\
\end{array}$ & $\frac{139.72}{\%}$ \\
\hline & 10500 & - & 9 & 0.61 & 29.02 & 36.1 & 1.0404 & 1.0090 & $\begin{array}{c}0.031 \\
4 \\
\end{array}$ & $3.11 \%$ \\
\hline & 10500 & - & 12 & 0.61 & 29.02 & 36.1 & 1.0578 & 1.1082 & $\begin{array}{c}- \\
0.050 \\
4\end{array}$ & $4.55 \%$ \\
\hline \multirow{4}{*}{$\begin{array}{c}\text { Q.Z. } \\
\text { Zhang } \\
{[37]}\end{array}$} & 77.79 & 1.5 & 8 & $\begin{array}{c}0.12 \\
2 \\
\end{array}$ & 27.22 & 3 & 0.0721 & 0.0667 & $\begin{array}{c}0.005 \\
4\end{array}$ & $8.10 \%$ \\
\hline & 77.79 & 1.65 & 8 & $\begin{array}{c}0.11 \\
9 \\
\end{array}$ & 27.10 & 3 & 0.0724 & 0.0663 & $\begin{array}{c}0.006 \\
0\end{array}$ & $9.05 \%$ \\
\hline & 77.79 & 1.85 & 8 & $\begin{array}{c}0.11 \\
5\end{array}$ & 26.93 & 3 & 0.0727 & 0.0795 & $\begin{array}{c}- \\
0.006 \\
9 \\
\end{array}$ & $8.68 \%$ \\
\hline & 77.79 & 2 & 8 & $\begin{array}{c}0.10 \\
5\end{array}$ & 26.65 & 3 & 0.0729 & 0.0851 & $\begin{array}{c}- \\
0.012 \\
1\end{array}$ & $14.22 \%$ \\
\hline
\end{tabular}
verification results are shown in Tab. 1.

Table 1 Model verification

ISSN: 0010-8189 
CONVERTER MAGAZINE

Volume 2021, No. 2

\begin{tabular}{|c|c|c|c|c|c|c|c|c|c|}
\hline 77.79 & 1.5 & 8 & $\begin{array}{c}0.12 \\
4\end{array}$ & 27.28 & 4 & 0.0739 & 0.0539 & $\begin{array}{c}0.020 \\
0\end{array}$ & $37.11 \%$ \\
\hline 77.79 & 1.65 & 8 & $\begin{array}{c}0.11 \\
8\end{array}$ & 27.06 & 4 & 0.0745 & 0.0601 & $\begin{array}{c}0.014 \\
4\end{array}$ & $23.96 \%$ \\
\hline 77.79 & 1.85 & 8 & $\begin{array}{c}0.11 \\
9\end{array}$ & 27.07 & 4 & 0.0743 & 0.0733 & $\begin{array}{c}0.001 \\
1\end{array}$ & $1.50 \%$ \\
\hline 77.79 & 2 & 8 & 0.11 & 26.74 & 4 & 0.0753 & 0.0805 & $\begin{array}{c}- \\
0.005 \\
3\end{array}$ & $6.58 \%$ \\
\hline 77.79 & 1.5 & 8 & 0.12 & 27.15 & 5 & 0.0752 & 0.0678 & $\begin{array}{c}0.007 \\
3\end{array}$ & $10.77 \%$ \\
\hline 77.79 & 1.65 & 8 & $\begin{array}{c}0.11 \\
5\end{array}$ & 26.96 & 5 & 0.0757 & 0.0723 & $\begin{array}{c}0.003 \\
4\end{array}$ & $4.70 \%$ \\
\hline 77.79 & 1.85 & 8 & $\begin{array}{c}0.11 \\
3\end{array}$ & 26.86 & 5 & 0.0759 & 0.0761 & $\begin{array}{c}- \\
0.000 \\
3\end{array}$ & $0.39 \%$ \\
\hline 77.79 & 2 & 8 & $\begin{array}{c}0.10 \\
8\end{array}$ & 26.67 & 5 & 0.0764 & 0.0813 & $\begin{array}{c}- \\
0.004 \\
9\end{array}$ & $6.03 \%$ \\
\hline 77.79 & 1.5 & 8 & $\begin{array}{c}0.13 \\
8\end{array}$ & 27.71 & 6 & 0.0738 & 0.0601 & $\begin{array}{c}0.013 \\
8\end{array}$ & $22.96 \%$ \\
\hline 77.79 & 1.65 & 8 & $\begin{array}{c}0.13 \\
3\end{array}$ & 27.54 & 6 & 0.0743 & 0.0696 & $\begin{array}{c}0.004 \\
6\end{array}$ & $6.61 \%$ \\
\hline 77.79 & 1.85 & 8 & 0.13 & 27.41 & 6 & 0.0745 & 0.0718 & $\begin{array}{c}0.002 \\
7\end{array}$ & $3.76 \%$ \\
\hline 77.79 & 2 & 8 & $\begin{array}{c}0.12 \\
5\end{array}$ & 27.24 & 6 & 0.0750 & 0.0745 & $\begin{array}{c}0.000 \\
5\end{array}$ & $0.67 \%$ \\
\hline
\end{tabular}

This verification selected the largest particle size test group $(D=8 \mathrm{~mm})$ involved in the Zhang Qizhe test ${ }^{[37]}$. Through comparison, it is found that the measured value from Zhang Qizhe's test is in good agreement with the calculated value. The reason for the larger error should be that the theoretical calculation formula deduced in this paper is the theoretical result obtained in the rectangular section, with no consideration of the influence of the slope, while the measured value given in the reference ${ }^{[37]}$ is the gravel incipient motion bottom velocity on the concave bank slope. For the measured data of Clayton and Pitlick ${ }^{[25]}$, the first to third columns of the table respectively represent the convex, middle and concave bank data. Through comparison, it is found that the calculated value is in good agreement with that of the middle and concave bank, while there is a large error for the convex bank (as shown in bold and underlined in Table 1). The reason for this error may be that the median size of the sediment on the convex bank of the bend is too small $(D=1 \mathrm{~mm}$, much smaller than the particle size range of the gravel), which exceeds the applicable range of the formula, and the convex bank of the bend often forms a point bar with siltation, resulting in the river bed slope to affect the incipient motion velocity. Dou Guoren ${ }^{[38]}$, Liu Xingnian $^{[39]}$ and Han Qiwei ${ }^{[11]}$ proposed when verifying the incipient motion flow velocity of large-size sediments that when the relative error is about $30 \%$, it can be considered that the formula obtained is consistent with the verification results of the measured data. It can be seen from Table 1 that the calculated value is in good agreement with the theoretical value, and the error basically meets the requirements, indicating that the theoretical formula deduced in this part can truly reflect the flow velocity required for the incipient motion of the gravel under the action of the bend flow to a certain extent.

\section{Influence of the Secondary Flow in a Bend on the Incipient Motion and Transport Direction of Sediment}

3.1 Influence on the incipient motion flow velocity

ISSN: 0010-8189

(C) CONVERTER 2020

www.converter-magazine.info 
In straight rivers, we do not consider the influence of the secondary flow of the bend and it is considered that the gravels are only affected by the main flow. That is, there is only the longitudinal velocity. According to the research results of Bai Yuchuan and Wang $\mathrm{Xin}^{[27]}$, the time average bottom velocity required for the incipient motion of the gravel under the mid-motion standard when the influence of the bend is not considered is shown in Formula (27).

$$
\bar{V}_{c b}=0.575 \varphi\left(\overline{\Delta_{x}^{\prime}}, \overline{\Delta_{z}^{\prime}}\right) \sqrt{\frac{4}{3} \frac{\rho_{s}-\rho}{\rho} g D}
$$

Where $\bar{V}_{c b}$ is the time average bottom velocity for the incipient motion of the gravel without considering the influence of the bend.

Then the ratio of the longitudinal time average bottom velocity required for the incipient motion of the gravel in a bend to the time average bottom velocity required for the incipient motion of the gravel in a straight river is:

$$
\frac{\widehat{u}_{s c b}}{\bar{V}_{c b}}=\frac{1}{\sqrt{1+\tan ^{2} \theta}} \leq 1
$$

Formula (28) shows that the existence of the included angle of the flow velocity in the bend (the existence of the secondary circulation) makes the sediment particles of the same size grade have the low longitudinal flow velocity required for the incipient motion under the same average incoming flow condition. And as the included angle increases, i.e. the strength of the secondary circulation increases, the longitudinal flow velocity required for sediment's incipient motion gradually decreases, as shown in Fig. 5.

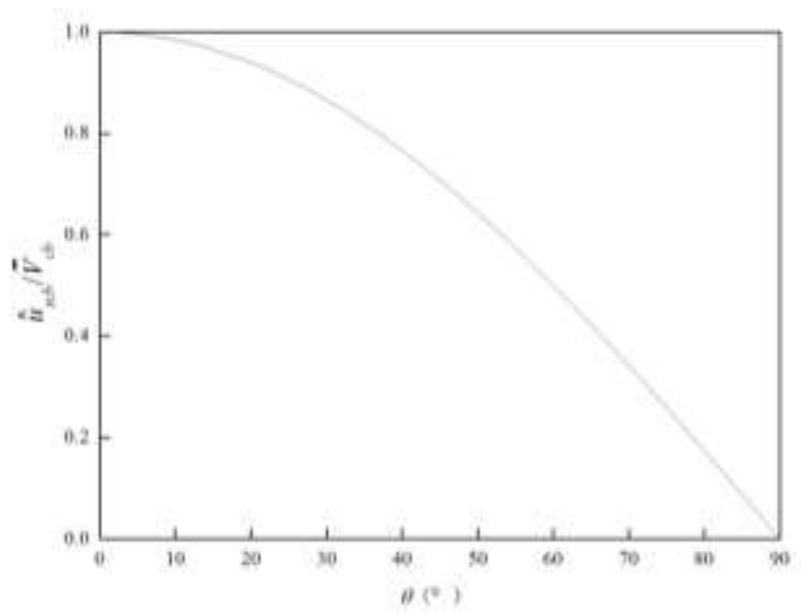

Fig 5: Relationship between $\theta$ and $\hat{u}_{s c b} / \bar{V}_{c b}$

It can also be seen from the figure that when the included angle of flow velocity is within the range of $0^{\circ}-20^{\circ}$, the amplitude of the change of the velocity with the angle is small; when $\theta>20^{\circ}$, the amplitude of the decrease of flow velocity increases rapidly, and when $\theta=60^{\circ}$, the longitudinal time average bottom velocity required for sediment's incipient motion is only $1 / 2$ of that in a straight river.

$\Delta u_{s}$ is defined as the difference between the longitudinal velocity component of the sediment and the longitudinal bottom flow velocity required for sediment incipient motion, i.e. $\Delta u_{s}=\hat{u}_{s c b}-\bar{V}_{c b}$. This value can reflect the difficulty of sediment incipient motion to a certain extent, and the greater the difference is, the easier it is for the sediment incipient motion. This value can also be regarded as the sediment transport rate, and the greater the difference is, the greater the transport rate will be after the incipient motion of the sediment. When the degree of

ISSN: 0010-8189 
curvature of the bend is certain, $\Delta u_{s}$ is unevenly distributed along the river width due to the uneven distribution of longitudinal flow velocity and lateral velocity in the bend along the width of the section ${ }^{[27]}$, as shown in Fig. 6.

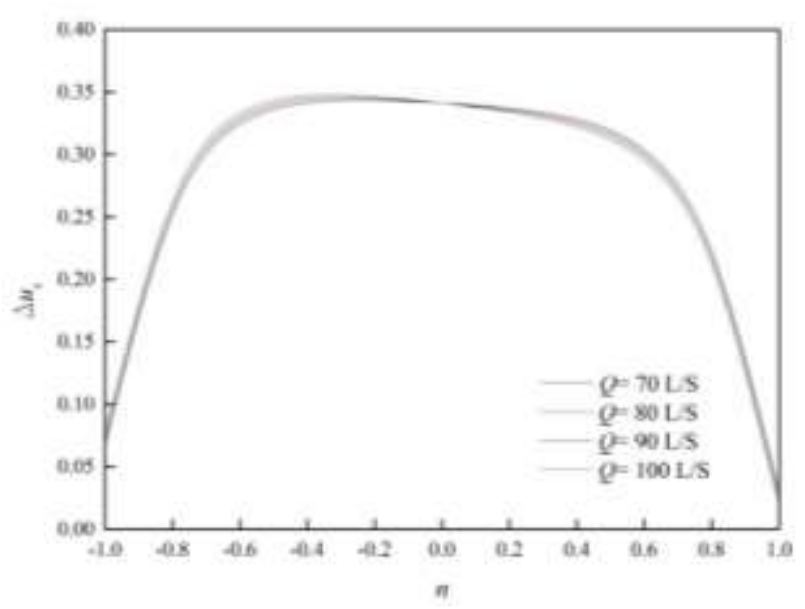

Fig 6: Transverse distribution of $\Delta u_{s}$

In the figure, the horizontal coordinate is positive towards the convex bank, i.e. $n>0$ is the convex bank. The picture shows the distribution of the velocity included angle along the river width under different incoming flow conditions (the calculation parameters are the same as the parameters of Zhang Qizhe's test ${ }^{[37]}$ ) under the premise of ensuring the incipient motion of gravel particles with a particle size of $8 \mathrm{~mm}$. It can be seen from the figure that under any incoming flow condition, the flow velocity difference along the width of the section is smaller on the near shore side, and the flow velocity difference increases rapidly within the range from the quay wall to $0.4 B$ from the quay wall, and then the varied range of the velocity difference is weakened when $n=-0.6 \sim 0.6$, and the velocity difference on the concave bank side is larger than that on the convex bank side. This distribution trend shows that it is not easy to move for the sediment on the side close to the quay wall, and the range of $n=-0.6 \sim 0.6$ should be a large area for sediment incipient motion, which is easy to form a sediment transport belt. At the same time, it is easier for the sediment to move on the concave bank side than that on the convex bank side. It can also be seen from the figure that as the intensity of the incoming flow increases, and the variation range of the velocity difference along the river width gradually increases in the large-area incipient motion area (within the range of $n=-$ 0.6 0.6). Such change can indicate that the greater the intensity of the incoming flow is in a river with the same degree of curvature, the more obvious the redistribution of the longitudinal velocity will be, and the more uneven the distribution of the difficulty of incipient motion of sediment along the width of the river will be. For a uniform gravel bed surface, the sediment on the concave bank side is easier to move, and it is more difficult for the sediment near the convex bank to move; for the uneven gravel bed surface, the incipient motion sediment particle size is larger on the concave side than that on the convex side. This phenomenon is consistent with the actual measurement results obtained by Clayton and Pitlick ${ }^{[25]}$ (Clayton and Pitlick found through field measurement that the particle size of the sediment on the concave bank is larger than that on the convex bank ${ }^{[25]}$ ). This makes it easy for the median size of the bed sediment on a relatively balanced non-uniform gravel bed surface to decrease from the concave bank to the convex bank in the bend where the secondary flow is fully developed, i.e. lateral sediment separation will occur on this bed surface.

\subsection{Influence on the direction of movement after incipient motion}

The uneven distribution of longitudinal velocity and lateral velocity in the bend along the width of the section ${ }^{[25]}$ will also produce an angle $\theta$ that is non-uniformly distributed along the width of the section, as shown in Fig. 7 .

ISSN: 0010-8189 


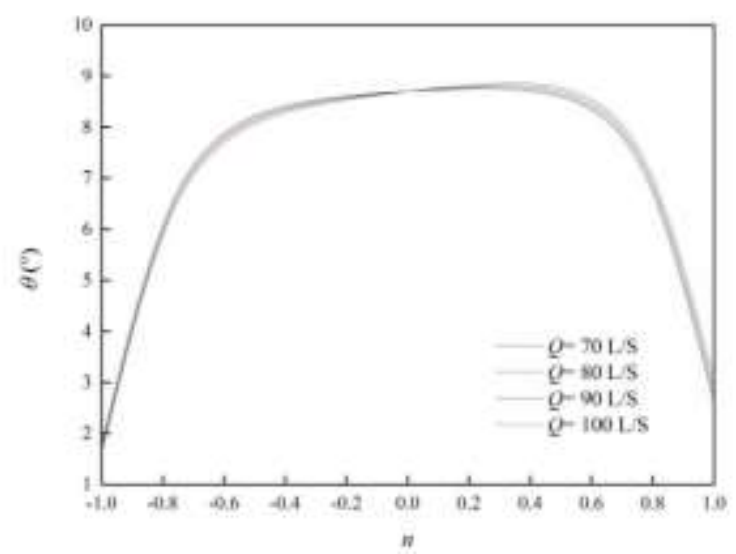

Fig 7: Transverse distribution of $\theta$

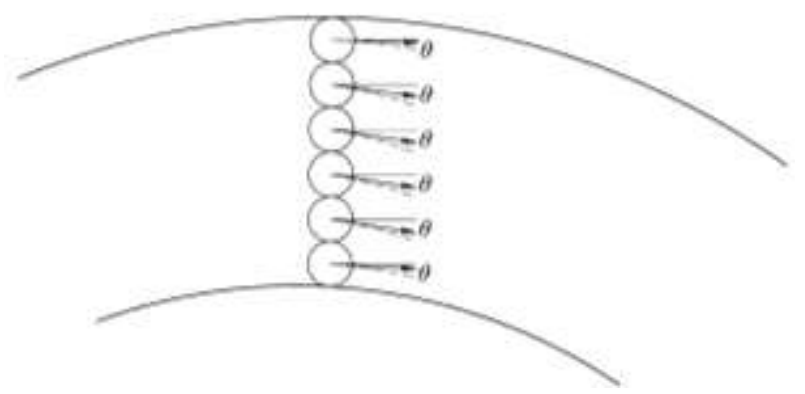

Fig 8: Direction of sediment motion

It can be seen from the figure that there is a non-uniform distribution of the included angle of velocity in the bend section along the river width. In any case of incoming flow, the included angle of flow velocity is smaller in the range from the quay wall to $0.4 B$, and the included angle of flow velocity is larger in the range of $n=-0.6 \mathrm{~B} \sim 0.6 \mathrm{~B}$ than that near the quay wall. The flow velocity at the bottom of the secondary circulation in the bend is directed from the concave bank to the convex bank. Therefore, it indicates that the greater the included angle of the flow velocity is, the more the movement direction of the sediment will be shifted to the convex bank after the incipient motion. That is, the stronger the secondary flow is, the more obvious the trend of lateral sediment transport will be, as shown in Fig. 8. The non-uniform distribution of the included angle of flow velocity in the bend section along the width of the river corresponds to the different degrees of different bank transport of sediment in the bend on the basis of the same bank transport. The included angle is smaller from the quay wall to $0.4 B$, and larger in the range of $n=-0.6 \sim 0.6$, indicating that the sediment particles in the nearshore area are mainly transported on the same bank after the incipient motion of the sediment particles, and as they approach the center of the river, the phenomenon of different-bank sediment transport is gradually becoming apparent. In the large-area incipient motion area (within the range of $n=-0.6 \sim 0.6$ ), the included angle of the sediment flow velocity on the concave bank side is smaller than that on the convex bank side. That is, when the rolling step length is constant after the sediment incipient motion, the closer to the concave bank side the sediment particles are, the longer the transport distance to downstream will be, and the shorter the transport distance to the convex bank will be. Under the combined effect of sand transport on the same bank and different banks, the bed surface shape in a bend is inevitably different from that in a straight river. At the same time, it can be seen from Fig. 7 that as the intensity of the incoming flow increases, the range of change of the included angle of velocity along the width of the river increases, and the included angle of movement of sediment particles becomes smaller on the concave bank side after the incipient motion, while it becomes larger on the convex bank side.

\section{Conclusions}

ISSN: 0010-8189

(C) CONVERTER 2020 
Based on the theoretical research of Bai Yuchuan and Wang Xin's existing three-dimensional water flow structure in a bend ${ }^{[27]}$ and gravel incipient motion under the influence of two-way exposure ${ }^{[17]}$, this paper has proposed the calculation formula of the velocity of gravel incipient motion under the action of bend flow, and relevant actual measurement data have been used for verification. The research shows that:

(1) Affected by the secondary flow in the bend, the sediment particles on the bed surface in the bend are affected by the combined action of the longitudinal and lateral water flow. The two-way flow velocity forms an included angle of flow velocity, which makes the longitudinal velocity required for the incipient motion of sediment to be reduced compared with that in a straight river. And the greater the intensity of the secondary flow in the bend is (the greater the degree of curvature of the bend is), the smaller the value of the longitudinal velocity required for incipient motion will be.

(2) For a river with a certain degree of curvature, due to the uneven distribution of the secondary flow intensity along the river width, the incipient motion velocity and transport direction of the sediment particles in the same section of the bend are also unevenly distributed along the river width. The reverse distribution of the angle and the velocity difference along the width of the river shows that the longitudinal main flow determines whether the sediment on the bed surface moves and the particle size, and the secondary circulation mainly affects the direction of sediment transport after the incipient motion.

(3) The incipient motion and transport of sediment in the bend section mainly occurs in the range of $n=-0.6 \sim 0.6$. The closer to the quay wall it is, the less the incipient motion of sediment is likely to occur. Under the action of the longitudinal main flow redistribution, in the range of $n=-0.6 \sim 0.6$, the sediment on the concave bank side is easier to move than that on the convex bank side.

(4) The sediment close to both banks of the bend section is mainly transported on the same bank. Under the action of the secondary flow, within the range of $n=-0.6 \sim 0.6$, the sediment transport across the bank is obvious, and sediment particles transport obliquely downstream. The closer to the concave bank it is, the longer the relative distance of sediment transport downstream will be.

(5) The non-uniformity of the incipient motion and transport direction of the sediment on the bed surface in the bend along the width of the river is the prerequisite for the lateral separation of the sediment in the bend.

(6) It is found through comparison and verification that the results calculated by the deduced critical incipient motion velocity expression are in good agreement with the relevant data, which shows that the formula is suitable for solving the incipient motion velocity of the gravels under the action of the bend flow to a certain extent.

\section{Acknowledgements}

This research was supported by National Natural Science Foundation of China (Grant No. 51809130, 51979132). Central Public Research Institutes Fundamental Research (Grant No. TKS190104, TKS190406, TKS20200303). Natural Science Foundation of Chongqing (Grant No. cstc2019jcyj-msxmX0599).

\section{References}

[1] Y.A. Wang, G.N. Yu, "Sediment prevention and treatment measures for Songhuajiang Dadingzishan navigation-power project", Annual Meeting 2008 of International Shipping Association and International Shipping Technology Seminar. 2008.

[2] S.Y. Cao, X.N. Liu, D. Fang, "Distribution of bedload size of the gravels in the Three Gorges of the

ISSN: 0010-8189

C CONVERTER 2020

www.converter-magazine.info 
Yangtze River", Journal of Hydroelectric Engineering, vol. 2, pp. 50-58, 1998.

[3] X.H. Zeng, "Discussion on the regulation project of sandy gravel shallow shoal channel", Pearl River Water Transport, vol. 7, pp. 32-33, 2000.

[4] H.A. Einstein, "The bedload function for sediment transportation in open channel flows", Tech Bulletin, No 1026, United States Dept of Agriculture, 1950.

[5] R.L. Misri, K.G. Ranga Raju, R.J. Garde, "Bed load transport of coarse nonuniform sediments", J Hydraul Eng-ASCE, vol. 110, no. 3, pp. 312-328, 1984.

[6] B.R. Samaga, K.G. Ranga Raju, R.J. Garde, "Bed load transport rate of sediment mixture", J Hydraul Eng-ASCE, vol. 11, pp. 1003-1018, 1986.

[7] M.K. Mittal, P.D. Porey, K.G. Ranga Raju, "Bed load transport of nonuniform sediment”, Proceedings of the Euromech 262 Colloquium on Sand Transport in Rivers, Estuaries and the Sea. Wallingford, U.K., 1990.

[8] P.L. Patel, K.G. Ranga Raju, "Fractionwise calculation of bed load transport", J Hydraul Res, IAHR, vol. 34, no. 3, pp. 363-379, 1996.

[9] Q.W. Han, "Sediment incipient motion law and incipient motion velocity", Sediment Research, vol. 2, pp. 11-26, 1982.

[10] Q.W. Han, M.M. He, "Statistical theory of sediment movement”, Beijing: Science Press, 1984.

[11] Q.W. Han, M.M. He, "Sediment incipient motion law and incipient motion velocity", Beijing: Science Press, 1999.

[12] X.N. Liu, E. Huang, "Research on the characteristics of wide-graded bedload transport", Sediment Research, vol.4, pp.14-17, 2000.

[13] Y.H. Chen, Y.C. Bai, "Non-uniform bedload movement characteristics under balanced sediment transport conditions", Journal of Basic Science and Engineering, vol.21, no.4, pp. 657-669, 2013.

[14] Y. Wu, Q.W. Han, Y.C. Bai, "Grouped incipient motion velocity of non-uniform sediment on slopes", Journal of Tianjin University, vol.45, no. 3, pp. 209-214, 2012.

[15] Y.C. Bai, Y.H. Chen, Q.W. Han, "Saltation movement mechanism of sediment particles", Journal of Tianjin University, vol. 45, no. 3, pp. 196-201, 2012.

[16] Y.C. Bai, H.J. Xu, D. Xu, et al, "Nonlinear dynamic characteristics of bedload movement process", Science in China Series E: Technical Science, vol. 36, no. 7, pp. 751-772, 2006.

[17] Y.C. Bai, X. Wang, Y.G. Cao, "Incipient motion of non-uniform coarse grain of bedload considering the impact of two-way exposure”, Sci China Tech Sci, vol. 56, no. 8, pp. 1896-1905, 2013.

[18] Y.J. Lu, H.Q. Zhang, "Study on the unbalanced sediment transport of non-uniform bedload in constant flow", Journal of Waterway and Harbor, no. 2, pp. 9-16, 1991.

[19] H. Teraguchi, H. Nakgawa, K. Kawaike, et al, "Effects of hydraulic structures on river morphological processes”, Int J Sediment Res, vol. 26, pp. 283-303, 2011.

[20] Y. Lu, Y.J. Lu, Y.M. Chiew, "Incipient motion of cohesionless sediments on riverbanks with ground water injection”, Int J Sediment Res, vol. 27, pp.111-119, 2012.

[21] T.H. Liu, L. Chen, B.L. Fan, "Experimental study on flow pattern and sediment transportation at a 90ºpen-channel confluence”, Int J Sediment Res, vol. 27, pp. 178-187, 2012.

[22] P.Y. Wang, S.Q. Zhao, J.D. Cai, "Study on bedload sediment transport belts in curved rivers", Journal of Sediment Research, vol. 2, pp. 43-48, 1995.

[23] Z.W. Li, C.M. Fang, "Law of bedload lateral sediment transport in bends and bed surface balance mechanism", Journal of Hydroelectric Engineering, vol. 31, no. 3, pp. 119-125, 2012.

[24] G. Parker, E.D. Andrews, "Sorting of bed load sediment by flow in meander bends", Water Resour Res, vol. 21, no. 9, pp. 1361-1373,1985.

[25] J.A. Clayton, J. Pitlick, "Spatial and temporal variations in bed load transport intensity in a gravel bed river bend", Water Resour Res, vol. 43, W02426, 2006.

[26] D.D. Jiao, X.J. Shao, G. Zhou, et al, "Selection of bedload transport direction in 3D water-sediment numerical simulation of bends", Journal of Hydrodynamics, vol. 23, no. 5, pp.546-553, 2008.

ISSN: 0010-8189

(C) CONVERTER 2020 
[27] Y.C. Bai, X. Wang, "Theoretical bend-flow solutions and velocity-dip phenomenon", J Hydraul Res, IAHR, vol. 55, no. 3, pp. 338-348, 2017.

[28] H. Johannesson, "Theory of river meanders", USA: University of Minnesota, 1988.

[29] H. Johannesson, G. Parker, "Secondary Flow in Mildly Sinuous Channel”, J Hydraul Eng-ASCE, vol. 115, no. 3, pp. 289-308, 1989.

[30] J. Guo, "Modified log-wake-law for smooth rectangular open channel flow", J Hydraul Res, IAHR, vol. 52, no. 1, pp. 121-128, 2014.

[31] J.B. Francis, "On the cause of the maximum velocity of water flowing in open channels being below the surface", Transactions of the American Society of Civil Engineers, vol. 7, no. 1, pp. 109-113, 1878.

[32] E.C. Murphy, “Accuracy of stream measurements”, USA: United States Geological Survey, 1904.

[33] F. Engelund, "Flow and bed topography in channel bends", J Hydr Eng Div-ASCE, vol.100, no. 3, pp. 1631-1648, 1974.

[34] J. Thompson, "On the flow of water round river bends", Proc Inst.Mech Eng, vol. 8, no. 6, 1879.

[35] S.C. Tong, G.X. Xu, "Study on the incipient motion velocity of sediment on the bank slope of the river", Journal of Hydraulic Engineering, vol. 39, no. 11, pp. 1167-1173, 2008.

[36] X. Xu, "Experimental study on the distribution characteristics of bedload transport belt at the end of the fluctuating backwater area of the Three Gorges", Chongqing: Chongqing Jiaotong University, 2015.

[37] Q.Z. Zhang, "Study on the erosion theory and stability of the side slope of the river roadbed", Chongqing: Chongqing Jiaotong University, 2004.

[38] G.R. Dou, "Discussion of the incipient motion velocity of sediment", Sediment Research, no. 6, pp. 1-9, 1999.

[39] X.N. Liu, S.Y. Cao, E. Huang, et al., "Incipient motion velocity of non-uniform sediment in the process of coarsening and refining", Sediment Research, vol. 4, pp. 10-13, 2000.

ISSN: 0010-8189 